\title{
PLA-Based Biodegradable and Cytocompatible Implant Materials: Material Development, Processing and Properties
}

\author{
Maike Bargmann ${ }^{1}$, Hans Kothe ${ }^{1}$, Bernd Steinhoff ${ }^{1}$, Ingo $\operatorname{Alig}^{1}$, Claudia Rode ${ }^{2}$, Ralf Wyrwa ${ }^{2}$ and Matthias \\ Schnabelrauch ${ }^{2}$ \\ 1. FraunhoferInstitute for Structural Durability and System Reliability LBF, Darmstadt 64289, Germany \\ 2. INNOVENT e.V., Prüssingstrasse 27B, 07745 Jena, Germany
}

Received: June 12, 2013 / Accepted: July 18, 2013 / Published: October 25, 2013.

\begin{abstract}
The influence of material composition and melt processing on filler dispersion, molar mass degradation, thermo-mechanical properties, biodegradability and cytocompatibility have been studied for composites of polylactide (PLA) and different biodegradable inorganic filler materials (e.g. calcium phosphate, calcium carbonate, pure and functionalized hydroxyapatites) as well as different filler amounts-varying from 0 to $40 \mathrm{wt} \%$. Due to their thermoplastic processability, biocompatibility and biodegradability the studied materials serve as model compounds for PLA-based orthopedic implant materials used in bone repair. Polymeric matrix material and fillers were melt-mixed using either a micro- or a laboratory-scale extruder. Test samples were prepared by injection molding of the compounds and characterized by gel permeation chromatography (GPC), differential scanning calorimetry (DSC), dynamical-mechanical analysis (DMA), micro computer tomography ( $\mu$-CT) and wide-angle X-ray scattering (WAXS). All measurements regarding mechanical properties show the samples to be suitable for non-load-bearing orthopedic applications. Cell colonization experiments with MC3T3-E1 and RAW 264.7-cells were performed and showed all samples to be cytocompatible, irrespective of the chosen filler type. Biodegradation and process-induced degradation of the molar mass were found to be slower for samples containing hydroxyapatite than for those containing calcium carbonate or calcium phosphate.
\end{abstract}

Key words: Polylactide composites, inorganic fillers, implants, melt processing, thermo-mechanical properties, degradation, biodegradability, cytocompatibility.

\section{Introduction}

Most orthopedic implants used in surgery are still made of titanium or non-degradable polymers that have to be removed in a second operation. Not only is there a risk of infection during each operation, but additionally, the implants themselves often lead to inflammatory responses of the surrounding tissue, requiring an earlier removal which disrupts the healing process. The use of biodegradable, biocompatible medical implants can

Corresponding author: Ingo Alig, Ph.D., research fields: fraunhofer institute for structural durability and system reliability LBF anddarmstadt and division plastics. E-mail: ingo.alig@lbf.fraunhofer.de. avoid or reduce these drawbacks [1-3]. In order to be suitable for a variety of orthopedic applications, the material and its degradation properties have to be adaptable, so as to match the bone properties and tissue repair rates required. Those can vary according to age, state of health, bone type and many other factors. Since the biochemical and mechanical requirements for implant materials are manifold (Table 1) and depend on the specific medical application [1, 4-6], a compromise between providing sufficient mechanical stability and guaranteeing adequate biological degradability and biocompatibility has to be found $[6,7]$. 
Table 1 Material requirements for orthopedic implants.

\begin{tabular}{lll}
\hline Mechanical stability of implant & $\begin{array}{l}\text { Biocompatibility of implant and } \\
\text { degradation products }\end{array}$ & Degradation rate and characteristics \\
\hline $\begin{array}{l}\text { Under different stresses: } \\
\text { Compression, tension, torsion }\end{array}$ & No toxicity/cytotoxicity & $\begin{array}{l}\text { Degradation rate compatible with bone } \\
\text { regeneration rate }\end{array}$ \\
$\begin{array}{l}\text { At different frequencies: } \\
\text { ca. } 0.01 \mathrm{~Hz}-10 \mathrm{~Hz}\end{array}$ & $\begin{array}{l}\text { degradation } \\
\begin{array}{l}\text { Compatibility to bone stiffness to avoid bone } \\
\text { atrophy and stress shielding }\end{array}\end{array}$ & $\begin{array}{l}\text { Support for cell growthand cell } \\
\text { proliferation }\end{array}$ \\
\hline
\end{tabular}

Accordingly, there is a need for research on biodegradable, biocompatible materials with sufficient mechanical strength to replace bone material or fixate fractures for the time span it takes the bone to regenerate. Ideally, the material's degradation rate should match the bone regeneration rate, so that stress shielding and bone atrophy is avoided $[2,8]$ and the new bone substance takes over when the implant's mechanical strength fails $[5,8]$. The degradation products should be resorbable or else be rapidly excreted by the body $[1,8]$.

Incorporation of biocompatible, inorganic fillers provides mineral for the new bone material (mineral resorption) and is expected to have other advantages besides. The use of certain fillers is expected to improve the mechanical properties as well as the biocompatibility and osteoconductivity of the implant $[2,9]$. Also, they may be used to buffer the $\mathrm{pH}$-value during the implant's degradation, thereby avoiding inflammatory responses [10]. As PLA degrades hydrolytically, the implant's degradation rate can be modified by choosing a filler exhibiting the right hydrophilic or-phobic behavior. A careful selection of the polymer-filler composition and the processing parameters allows to influence the implant properties, thereby adapting them to specific medical needs. To that end, it is necessary to understand the relation between material composition, processing conditions and final properties, including biodegradability and biocompatibility $[6,8,11]$. Therefore, the investigation of the complete process chain and life cycle of the implant material (Fig. 1) (from polymer synthesis, compounding and injection molding to biodegradability and biocompatibility) has been included in this study.

Due to their thermoplastic processability, biodegradability and biocompatibility, composites of polylactide (PLA) and inorganic filler materials (calcium phosphate, calcium carbonate, pure and various functionalized hydroxyapatites (HAP)) have been studied. In the human body PLA is hydrolytically degradedby random chain scission to lactic acid, carbon dioxide and water and completely metabolized [3, 12]. As PLA exhibits slow degradation rates, it is a good candidate for implants used in bone fracture fixation [8], where implants have to retain their mechanical strength for a few months. All inorganic filler materials used in this study are easily resorbable by the human body. HAP especially is very similar to the mineral component present in human bones and teeth [3]. The polymeric matrix material and the fillers were melt-mixed in a micro-extruder and the compounds injection-molded. For high filler amounts a laboratory-scale extruder was used. The influence of processing conditions on filler dispersion, process-induced degradation, biodegradation, thermo-mechanical properties, crystallinity and biochemical characteristics, which are all factors

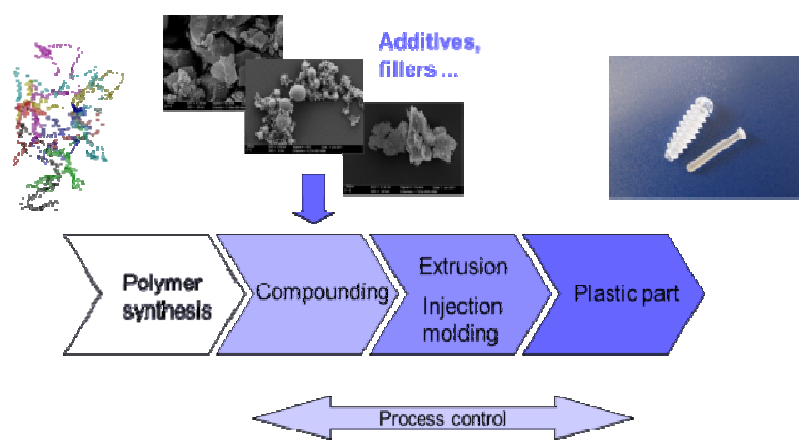

Fig. 1 Schematic of the implant material's process chain and life cycle. 
critically contibuting to the mechanical properties and degradation behavior of the implant [8], is investigated.

\section{Experimental Setup: Materials and Methods}

Commercially available PLA 4042D by nature works (Blair, Nebraska, USA) was used as matrix polymer. The molar mass of the material was $\mathrm{M}_{\mathrm{w}}=218,000$ with $\mathrm{M}_{\mathrm{w}} / \mathrm{M}_{\mathrm{n}}=1.25$. Filler materials synthesized were calcium carbonate $\left(\mathrm{CaCO}_{3}\right)$, calcium phosphate $\left(\mathrm{Ca}_{3}\left(\mathrm{PO}_{4}\right)_{2}\right)$ and hydroxyapatite (HAP), both pure and functionalized (with lactide-modified surface, carbonated or both) (

Table 2). The chemical modification of the filler materials was realized according to literature procedures [13]. The hydrophobic calcium carbonate was prepared by carbonation of calcium hydroxide in the presence of oleic acid. Calcium phosphate was synthesized by continuous mixing of an aqueous solution of calcium acetate with an aqueous solution of potassium dihydrogen phosphate and potassium carbonate at a $\mathrm{pH}$-value of 10 [10]. Hydroxyapatite and carbonated hydroxyapatite were prepared in a one-step co-precipitation process based on the reaction of calcium hydroxide and orthophosphoric acid at $80{ }^{\circ} \mathrm{C}$ [14]. In the case of carbonated hydroxyapatite, ammonium carbonate was added to the reaction mixture. Modification of hydroxyapatite and carbonated hydroxyapatite with poly-L-lactide was realized in a melt of L-lactide with stannous octoate as catalyst [15].

The PLA and fillers were melt-mixed by a twin-screw micro-extruder (DSM micro 5) atscrew speeds between 50 and $250 \mathrm{rpm}$. The injection-molded samples were rectangles of $50 \mathrm{~mm} \times 10 \mathrm{~mm} \times 1.5 \mathrm{~mm}$ in size. Samples with filler amountsof $10 \%$ and higherwere produced using a twin-screw laboratory-scale extruder (Haake PTW 16/25) at screw speeds of 20-300 rpm.

To investigate the influence of processing conditions on filler dispersion, process-induced degradation, biodegradation, thermo-mechanical properties and biochemical characteristics the following methods were used and the results compared.

Gel permeation chromatography (GPC) using a Shimadzu equipped with a SIL-10A auto injector, CTO-10AC column oven, SCL-10A system controller, LC-20AD pump, SPD-10A UV detector and RID-10A RI detectorwas employed to determine process-induced and biological degradation by measuring the molar mass distribution before and after. For each sample two measurements were averaged. The solvents used were THF and $\mathrm{CHCl}_{3}$.

The thermal characteristics of the samples (glass transition, cold crystallization, melting, etc.) were measured by differential scanning calorimetry (DSC) (Mettler Toledo $823^{\mathrm{e}}$ ): The samples were heated repeatedly from $0{ }^{\circ} \mathrm{C}$ to $200{ }^{\circ} \mathrm{C}$ at $10 \mathrm{~K} / \mathrm{min}$ and cooled similarly, with the third heating cycle holding at $110{ }^{\circ} \mathrm{C}$ for $5 \mathrm{~min}$ to allow complete crystallization, before cooling down again. The fourth heating cycle was identical to the first two.

Further morphological information was gathered bydynamical-mechanical analysis (DMA), using anARES rheometer (TA Instruments, Waters LLC, USA) to measure the real (G') and imaginary part (G') of the dynamic shear modulus of the injection-molded samples. The measurements were conducted at $1 \mathrm{~Hz}$,

Table 2 Inorganic fillers used.

\begin{tabular}{lll}
\hline Name and formula & Modification & Particle size $(\mu \mathrm{m})$ \\
\hline Calcium carbonate $\mathrm{CaCO}_{3}$ & Oleic acid & $1-20$ \\
Calcium phosphate $\mathrm{Ca}_{3}\left(\mathrm{PO}_{4}\right)_{2}$ & $\mathrm{CaCO}_{3}$ & $0.1-2$ \\
Hydroxy-apatite $(\mathrm{HAP}) \mathrm{Ca}_{10}\left(\mathrm{PO}_{4}\right)_{6}(\mathrm{OH})_{2}$ & Pure, precipitated & $0.1-0.2$ \\
Hydroxy-apatite $(\mathrm{HAP}) \mathrm{Ca}_{10}\left(\mathrm{PO}_{4}\right)_{6}(\mathrm{OH})_{2-\mathrm{y}}\left(\mathrm{C}_{6} \mathrm{H}_{8} \mathrm{O}_{4}\right)_{\mathrm{y}}$ & Lactide-modified surface & $0.1-0.2$ \\
Carbonated HAP $(\mathrm{CHAP}) \mathrm{Ca}_{10-\mathrm{x}}\left(\mathrm{PO}_{4}\right)_{6-\mathrm{x}}\left(\mathrm{CO}_{3}\right)_{\mathrm{x}}(\mathrm{OH})_{2-\mathrm{x}}$ & Carbonated & $0.1-0.6$ \\
Carbonated HAP $(\mathrm{CHAP}) \mathrm{Ca}_{10-\mathrm{x}}\left(\mathrm{PO}_{4}\right)_{6-\mathrm{x}}\left(\mathrm{CO}_{3}\right)_{\mathrm{x}}(\mathrm{OH})_{2-\mathrm{x}-\mathrm{y}}\left(\mathrm{C}_{6} \mathrm{H}_{8} \mathrm{O}_{4}\right)_{\mathrm{y}}$ & Lactide-modified and carbonated & $1-4$ \\
\hline
\end{tabular}


while heating the samples from $0{ }^{\circ} \mathrm{C}$ to $140{ }^{\circ} \mathrm{C}$ at $2 \mathrm{~K} / \mathrm{min}$.

Filler dispersion was gauged by micro computer tomography $(\mu-\mathrm{CT})$ using a SkyScan 1072-100. The resolution of the $\mathrm{x}$-ray images is $2.2 \mu \mathrm{m} / \mathrm{Pixel}$; the sample area investigated was approximately $2.3 \times 2.3$ $\mathrm{mm}^{2}$.

Crystallinity was measured by DSC and for some samples verified with wide-angle $\mathrm{X}$-ray scattering (WAXS) measurements covering angles $2 \Theta$ from $2^{\circ}$ to $40^{\circ}$ in $0.1^{\circ}$ steps at $10 \mathrm{~s} / \mathrm{step}$, using a Siemens D500-goniometer.

The inorganic filler particle size was examined by scanning electron microscopy (SEM) (Supra 55VP; Zeiss, Oberkochen, Germany). Gold was sputtered onto the samples to ensure sufficient electrical conductivity. The images were taken using an InLens-detector with $5 \mathrm{keV}$ excitation energy.

To determine the in-vitro cytocompatibility the samples were disinfected with 70\%-ethanol, rinsed twice with PBS and stored in cell-culture medium. Afterwards, the medium was discarded and samples were incubated with 25,000 cells $/ \mathrm{cm}^{2} \mathrm{MC} 3 \mathrm{~T} 3-\mathrm{E} 1-\mathrm{cells}$. The nutrient medium was changed daily. After 1 and 4 days the samples were withdrawn and live/dead-stained using fluorescein diacetate and GelRed $^{\circledR}$ dyes. An Axiotech microscope (Zeiss, Jena, Germany) was used to monitor green and red fluorescence.

To determine extractable cytotoxical components the samples were extracted with nutrient medium after 7, 14 and 21 days at $37{ }^{\circ} \mathrm{C}$. MC3T3-E1-cells were incubated with the extracts for 24 hours. The extracts were withdrawn and the WST-1 reagent, a water soluble tetrazolium salt, was added. MC3T3-E1-cells with nutrient medium act as a positive control only. The absorbance of the samples was measured at a wavelength of $450 \mathrm{~nm}$, employing a microtiter plate reader (Model550, Bio-Rad-Laboratories $\mathrm{GmbH}$, München, Germany).
Osteoclast genesis was evaluated by colonization with RAW 264.7-cells. The cells were seeded onto the samples and stimulated with RANKL ("Receptor Activator of NF- $\kappa \mathrm{B}$ Ligand" protein). The staining was realized by DAPI (4', 6-diamidino-2-phenylindole) for the nuclei and Fluorescein-Phalloidine for actin rings. After 3 days the nutrient medium was changed. The samples were withdrawn after 7 days and blue and green fluorescence was monitored by an axiotech microscope (Zeiss, Jena, Germany).

The in-vitro degradation was investigated by monitoring the samples's changes in weight, molar mass and $\mathrm{pH}$-value during immersion in $3 \mathrm{ml}$ of phosphate buffered saline (PBS) at $37^{\circ} \mathrm{C}$. The medium was changed weekly. To determine the weight loss, every 14 days the samples were removed, washed with distilled water and vacuum dried before being weighed. The molar mass loss was determined every 28 days. The $\mathrm{pH}$-value during immersion of the samples in PBS was measured in regular intervals of 7 days.

\section{Results and Discussion}

\subsection{Melt Mixing and Filler Dispersion}

To characterize the effects of melt mixing and injection molding on the implant material and correlate the results to the processing conditions, the filler dispersion in the injection molded samples was evaluated. Fig. 2showsX-ray images for samples melt-mixed at $150 \mathrm{rpm}$ containing $5 \mathrm{wt} \%$ filler. A difference in the quality of dispersion depending on the filler type used is obvious and suggests that HAP-based fillers are less finely dispersed than $\mathrm{CaCO}_{3}$ and $\mathrm{Ca}_{3}\left(\mathrm{PO}_{4}\right)_{2}$ (not shown).

Also, a dependence of filler dispersion on screw speed and the amount of filler was found (Fig. 3). As expected, at $20 \mathrm{rpm}$, samples containing higher amounts of HAP (20 wt.\%) show larger agglomerates than those containing less filler (5 wt.\%), while at high screw speeds the dispersion is equally good, with no discernible difference for the different filler amounts. 

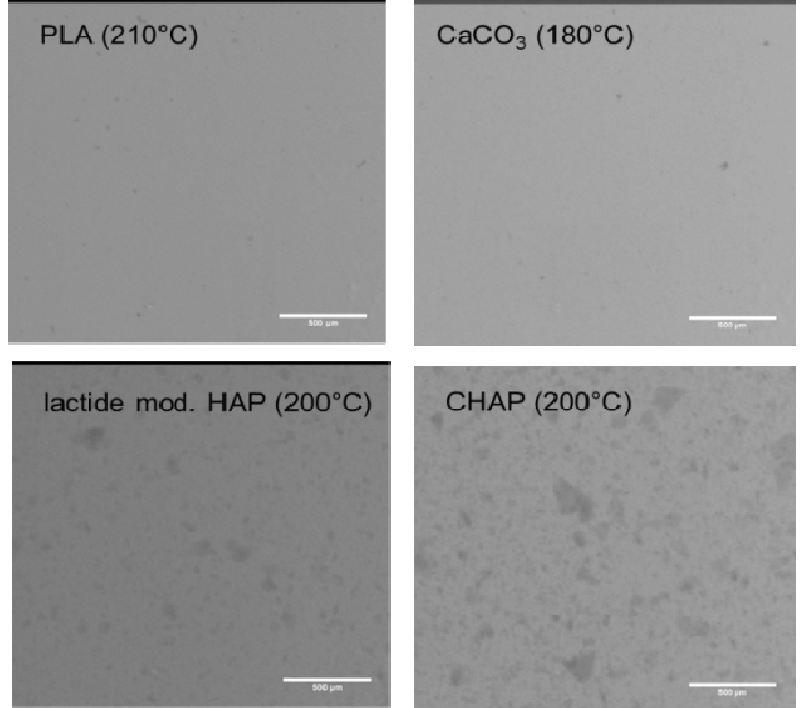

Fig. 2 Micro-computer-tomography images indicating the degree of dispersion for samples of PLA containing different filler types (at $5 \mathrm{wt}$ \%) compared to one of pure PLA. All samples were melt-mixed by a micro-extruder at $\mathrm{v}=150$ rpm.

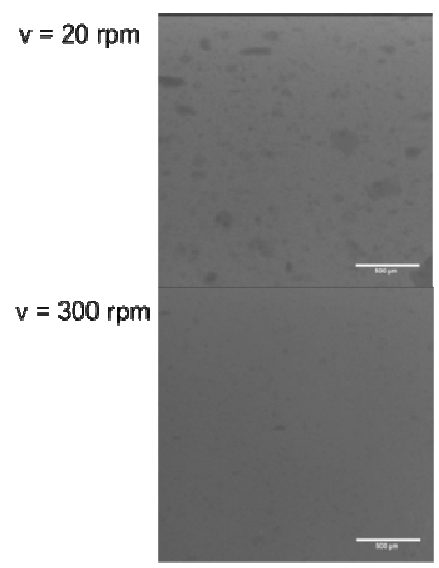

PLA +5 Wt.\% HAP

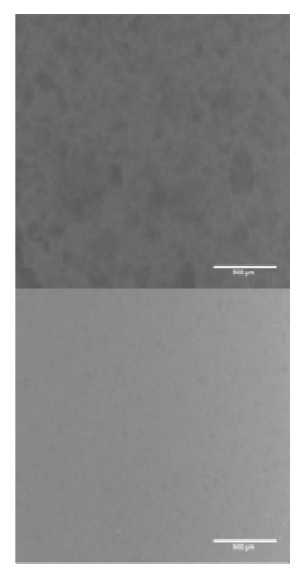

PLA +20 wt. \% HAP
Fig. 3 Micro-computer-tomography images indicating the degree of dispersion for different screw speeds and filler amounts. The samples were melt-mixed by a laboratory-scale extruder at $\mathrm{T}=200{ }^{\circ} \mathrm{C}$.

\subsection{Process-Induced Degradation}

Due to its thermal instability, the molecular weight of PLA decreases during melt mixing and injection molding [8]. The process-induced degradation was estimated by measuring the molar mass distribution for samples extruded at different processing parameters. The main parameters include temperature, screw speed, filler type and filler amount.
The temperature dependence was investigated by extruding samples at a fixed screw speed of $150 \mathrm{rpm}$ and different temperatures, with the lower temperature limit being $180{ }^{\circ} \mathrm{C}$, due to the high melting point of PLA (ca. $150-170{ }^{\circ} \mathrm{C}$ ), and the upper limit of $210{ }^{\circ} \mathrm{C}$. At temperatures higher than that, degradation was already optically visible and the polymer too fluid to be processed in the micro-extruder.

Screw speeds were varied from $50-250 \mathrm{rpm}$ for samples processed at a temperature of $180{ }^{\circ} \mathrm{C}$ to determine the screw speed dependence. Fig. 4 shows the results for different screw speeds and different extruder temperatures for samples containing $5 \mathrm{wt} . \%$ $\mathrm{CaCO}_{3}$.

The dependence of molar mass reduction on processing temperature was found to be linear, with the molar mass degrading more rapidly with highertemperature, meaning higher energy input (Fig. 4b). The screw speed influences the molar mass
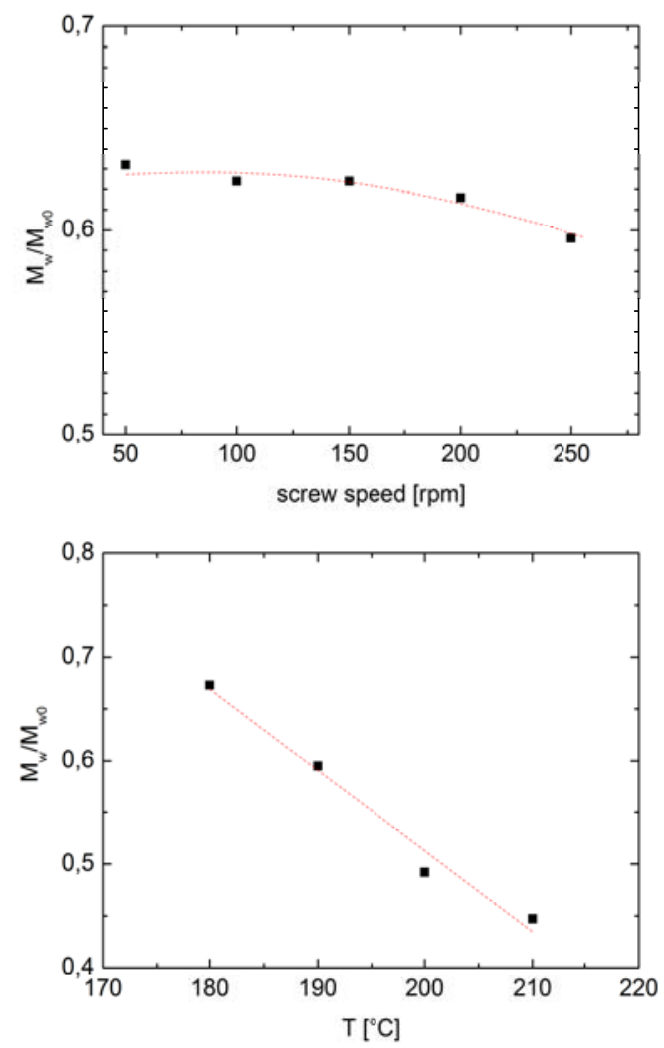

Fig. 4 Influence of screw speed (a) and processing temperature (b) on relative molar mass reduction during compounding and injection molding. 
reduction as well, albeit not linearly. Higher screw speeds result in lower molar mass, which can be attributed to the higher specific mechanical energy transferred to the material by the extruder's screws (Fig. 4a). The specific mechanical energy can be expressed as SME $=(2 \pi \omega \tau) / \mathrm{Q}$, with $\omega\left(1 / \mathrm{s}^{-1}\right)$ : screw speed, $\tau(\mathrm{Nm})$ : torque and $\mathrm{Q}(\mathrm{kg} / \mathrm{s})$ : throughput.

Experiments with higher filler amount were conducted on the laboratory-scale extruder for samples containing HAPat a previously determined optimum temperature of $200{ }^{\circ} \mathrm{C}$. Filler amounts ranged from 5 wt. $\%$ to 40 wt. $\%$. 40 wt. $\%$ was the limit of processability, as the materialbecomes increasingly brittle. At filler amounts higher than 40 wt.\% the material couldn't be smoothly extruded and the resulting data is not reliable. The GPC measurements show that there is a linear dependence of molar mass reduction on HAP amount (Fig. 5a). A probable explanation is that this is due to the initiation of the hydrolytical degradation process by the water contained in the HAP powder.

Finally, the influence of the filler type was investigated. The filler amount was 5 wt.\% for all samples and the processing temperature was the lowest possible for the PLA/filler combination (either $180{ }^{\circ} \mathrm{C}$ or $200{ }^{\circ} \mathrm{C}$ ) to avoid unnecessary degradation due to temperature. As can be seen in Fig. 5b, samples containing $\mathrm{CaCO}_{3}$ or $\mathrm{Ca}_{3}\left(\mathrm{PO}_{4}\right)_{2}$ exhibited higher degradation than the ones containing HAPs, either pure

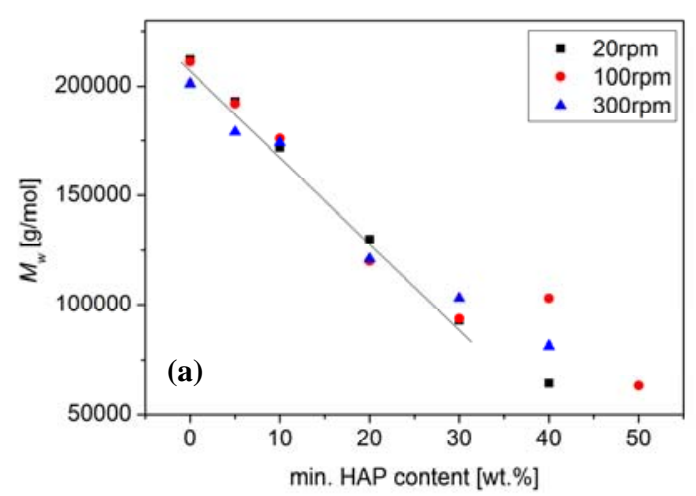

Fig. 5 (a) Influence of the filler amount on relative molar mass reduction during compounding at $200{ }^{\circ} \mathrm{C}$ for samples containing mineral HAP and (b) the influence of filler type on relative molar mass reduction during compounding (micro-extruder). or modified. The relative molar mass after processing was about 0.75 for those with HAPs and around 0.6 or lower for those with $\mathrm{CaCO}_{3}$ or $\mathrm{Ca}_{3}\left(\mathrm{PO}_{4}\right)_{2}$, even though processing temperatures were $20{ }^{\circ} \mathrm{C}$ lower for those samples. An additional, very pure commercial calcium carbonate ("S-Kalk") was tested as filler material and resulted in higher molar mass (ca. 0.7) after processing than the $\mathrm{CaCO}_{3}$-oleic acid that was used. It is therefore probable that the oleic acid component present in the initial $\mathrm{CaCO}_{3}$, which was introduced to facilitate contact between polymer matrix and filler, is in fact responsible for advancing degradation during processing. None of the HAP modifications showed any marked difference in effect.

The GPC measurements show that to reduce process-induced degradation, sufficiently low extruder temperatures and filler amounts should be chosen, while screw speed - in the range of speeds investigated - affects mainly the dispersion but the degradation very little. HAP-filled (modified and unmodified) samples show the highest remaining molar masses after injection molding.

\subsection{Thermo-Mechanical Properties}

The thermo-mechanical properties of biomaterials closely correlate with their chemical structure, especially the crystallinity $[4,5,16,17]$. The material'scrystallinity in turn directly influences the biodegradation through hydrolyzation $[1,18,19]$, which

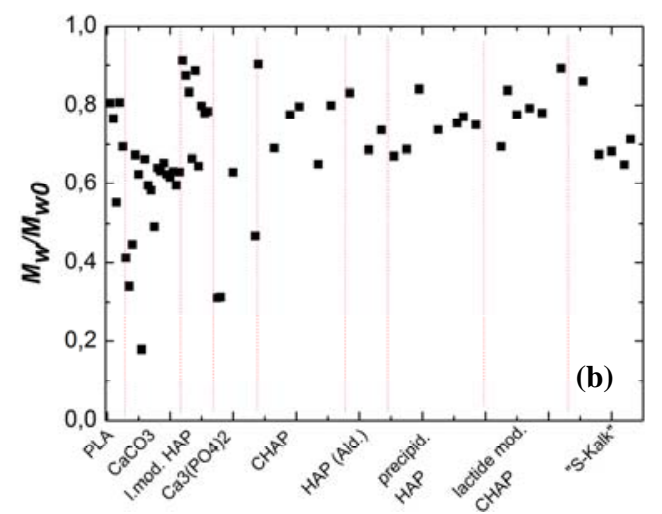


differs depending on the amount of amorphous and crystalline parts of the sample, as the degradation initially takes place chiefly in the amorphous phase $[12,19]$. Therefore, the injection-molded samples's thermo-mechanical behavior and crystallinity were evaluated by DSC, DMA and WAXS. The measurements show that the samples are largely amorphous after the manufacturing process, which is a result of the cooling rates typically prevalent during/after injection molding. Crystallinity is known to affect the rate of biodegradation, the higher the sample's crystallinity, the slower the degradation $[1,3$, $8,17,20]$, so that a good understanding of the processing parameters resulting in either amorphous or semi-crystalline samples is necessary to manipulate the sample characteristics to fit application requirements.

In Fig. 6, the heating cycles of a DSC measurement are depicted separately for a sample containing lactide-modified HAP. The glass transition of the
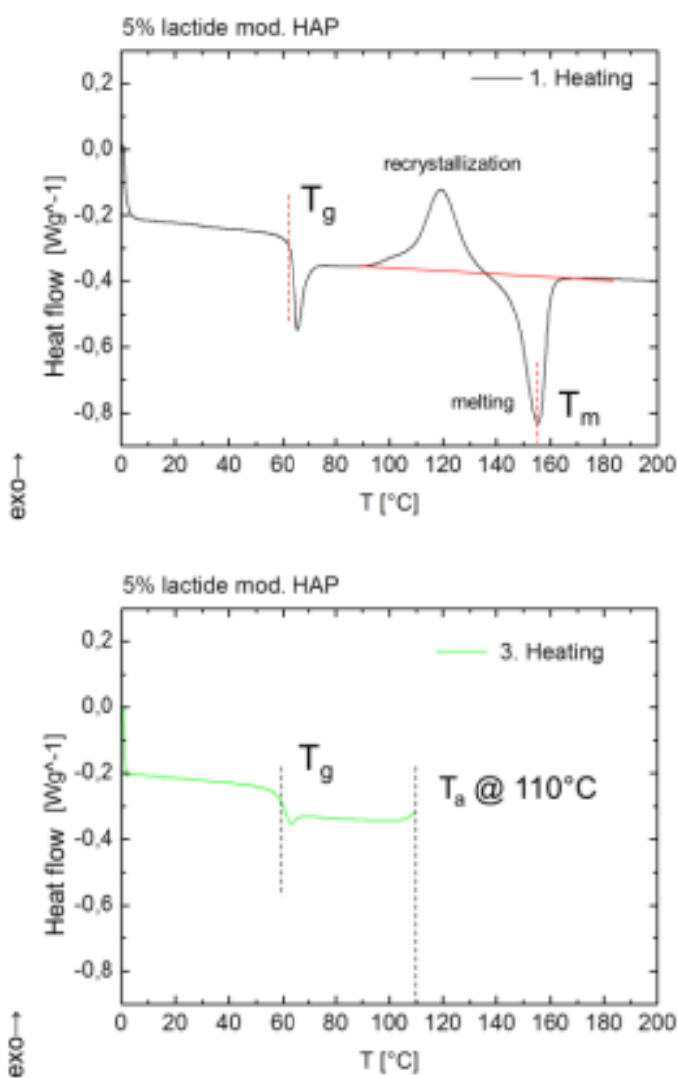

sample is at around $55-60{ }^{\circ} \mathrm{C}$, with cold crystallizationbetween approximately $90 \quad{ }^{\circ} \mathrm{C}$ and $130{ }^{\circ} \mathrm{C}$, after which melting starts, with $\mathrm{T}_{\mathrm{m}}=155^{\circ} \mathrm{C}$. The second and third cycles show the same characteristics. The fourth heating cycle exhibits a less pronounced $T_{g}$ and no cold-crystallization peak, thereby confirming that the sample was fully crystallized completely during the the third cycle.

This thermo-mechanical behavior was found for all samplesprocessed on the micro- and the laboratory-scale extruder, and differs only slightly for different filler types as can be seen in Fig. 7. Therefore, the filler type does not have any relevant influence on the thermal characteristics exhibited by the injection-molded samples. Higher filler amounts result in a shift of the cold-cystallization peak towards lower temperatures (Fig. 7b), probably due to anucleating effect of the mineral particles orthe different initial molar masses after the process-induced degradation.
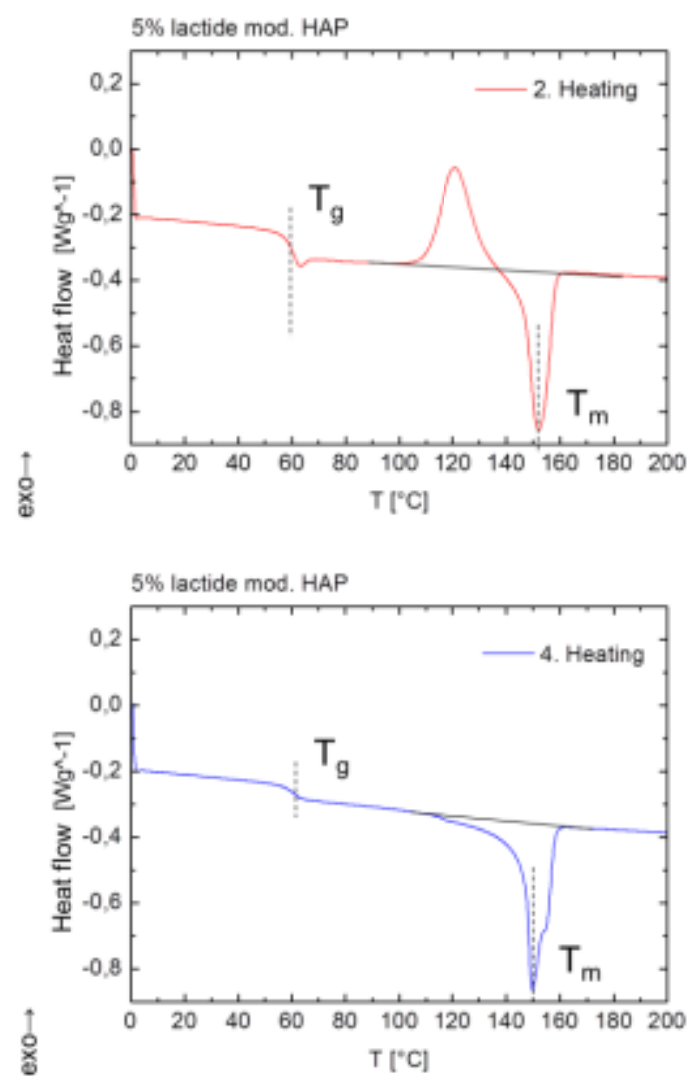

Fig. 6 The DSC heating cycles for a sample of PLA 4042D + 5\% lactide-modified HAP. The heating rate was $10 \mathrm{~K} / \mathrm{min}$. During the 3rd heating the sample was annealed at $T_{a}=110{ }^{\circ} \mathrm{C}$ for $5 \mathrm{~min}$. 


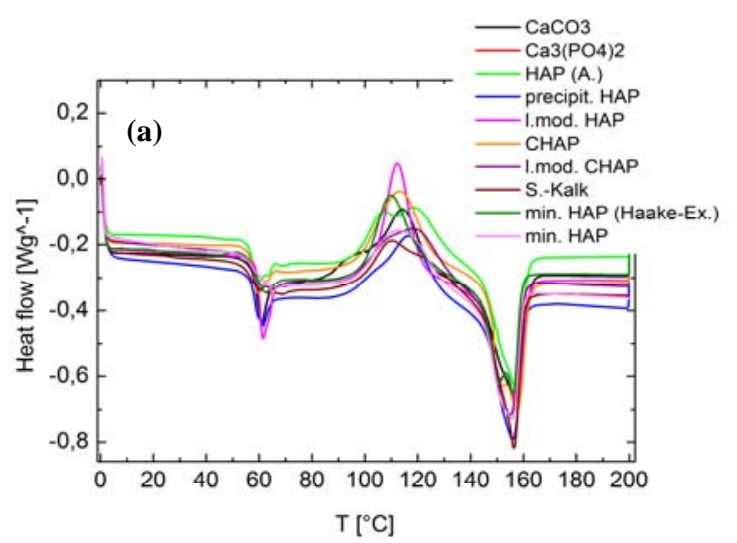

(a)

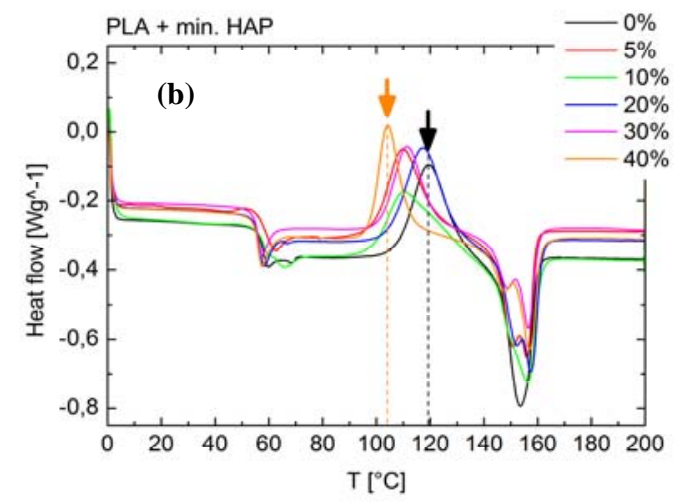

(b)

Fig. 7 1st heating cycle of DCS measurements for PLA 4042D with different filler type (a) and filler amount (b) (heating rate: $10 \mathrm{~K} / \mathrm{min})$.

Further measurements yielded the same general thermo-mechanical behavior for samples extruded at different processing parameters (extruder temperature and screw speed).

The shape of the curves measured in the dynamical-mechanical analysis confirms the samples to be largely amorphous, an example is shown in Fig. 8. For samples containing $5 \mathrm{wt} . \%$ fillerthe glass transition was measured to be at around $57{ }^{\circ} \mathrm{C}$, irrespective of filler type (Fig. 9a). Furthermore, DMA showed shear moduli of 1.1-1.8 GPa at approximately body temperature $\left(37{ }^{\circ} \mathrm{C}\right)$ (Fig. 10a). These values are sufficient for non-load-bearing implant applications that require an additional exterior fixation (plaster cast, splint, bandage etc.), for example the fixation of comminuted fractures, or fractures of radius, ulna or bones of the hand. For load-bearing bones the modulus

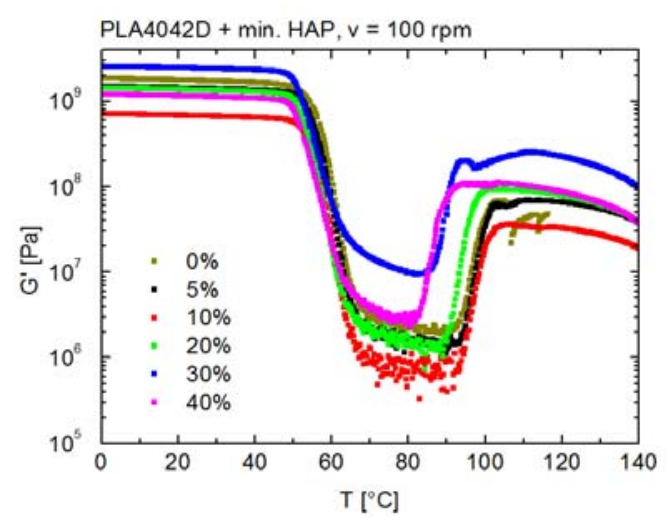

(a) of an implant material would have to be much higher (e.g., up to $\mathrm{G}=7 \mathrm{GPa}$ and $\mathrm{E}=20 \mathrm{GPa}$ for mandibular bone $[10,21])$. There was no notable dependence of modulus on filler type or dispersion, which is directly influended by the screw speed during processing. Also, increasing the sample's filler amount from 0 to $40 \mathrm{wt} . \%$ resulted in lower glass transition temperatures around $52{ }^{\circ} \mathrm{C}$, but did not increase the modulus (Fig. 9 and Fig. $10 \mathrm{~b}$ ). This means other ways of increasing the implant's modulus for load-bearing applications need to be considered.

For selected samples WAXS measurements were carried out, after the injectionmolding process as well as after further heating to a temperature of $140{ }^{\circ} \mathrm{C}$ (during DMA measurements). Fig. 11 shows a comparison of the results. The injection-molded sample was found to be amorphous. After heating, the

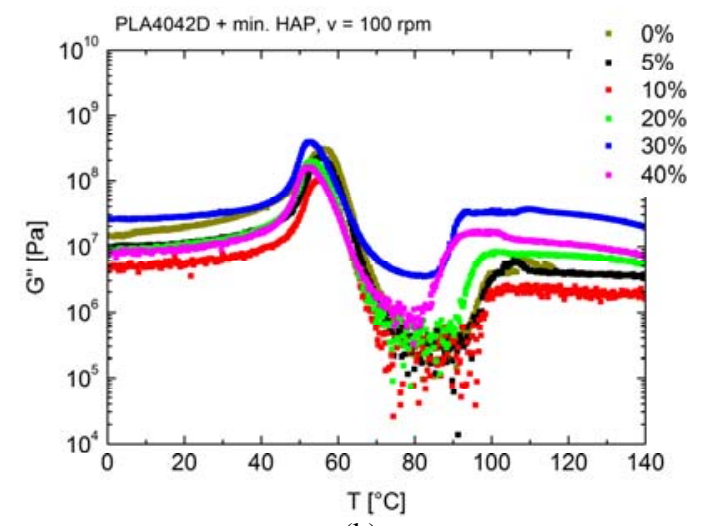

(b)

Fig. 8 (a) Real and (b) imaginary part of the shear modulus measured by DMA, exemplarily for PLA 4042D containing different filler amounts. 


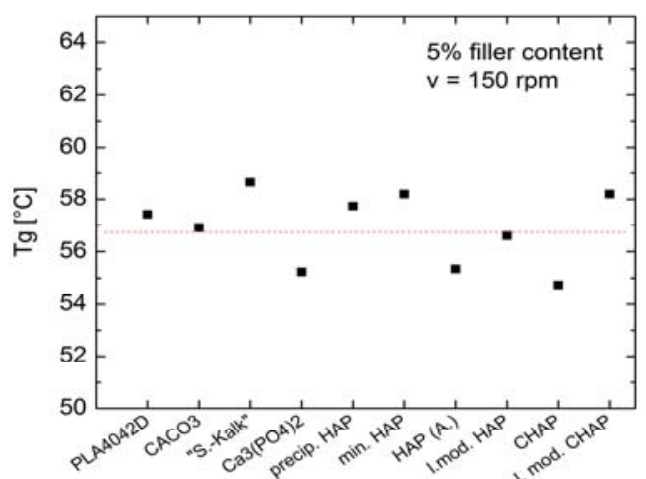

(a)

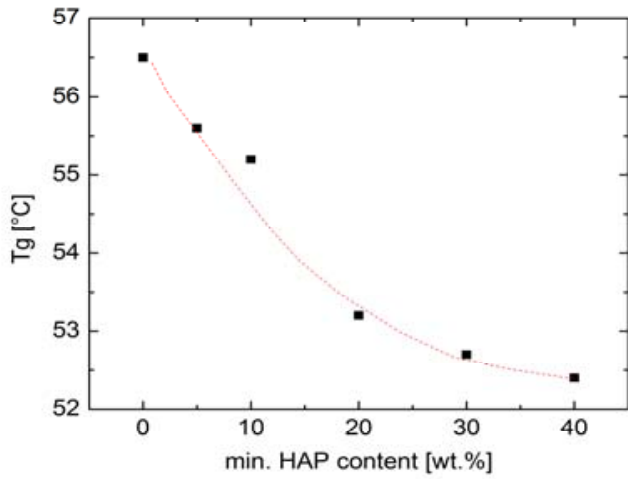

(b)

Fig. 9 Glass temperature for PLA 4042D containing (a) different filler types and (b) different filler amounts.

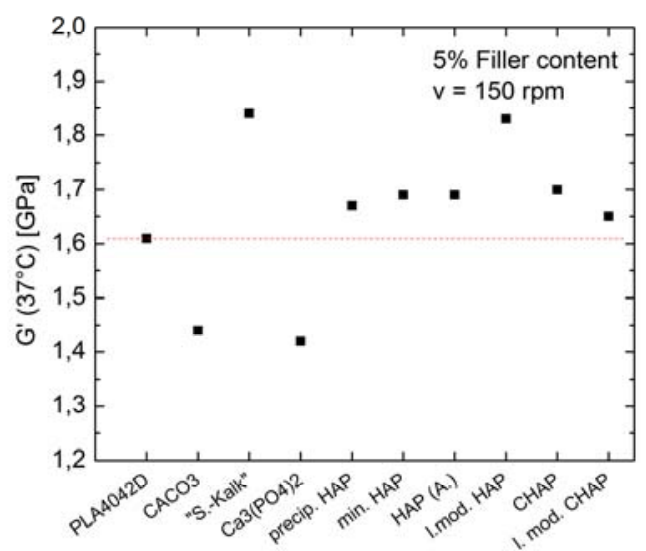

(a)

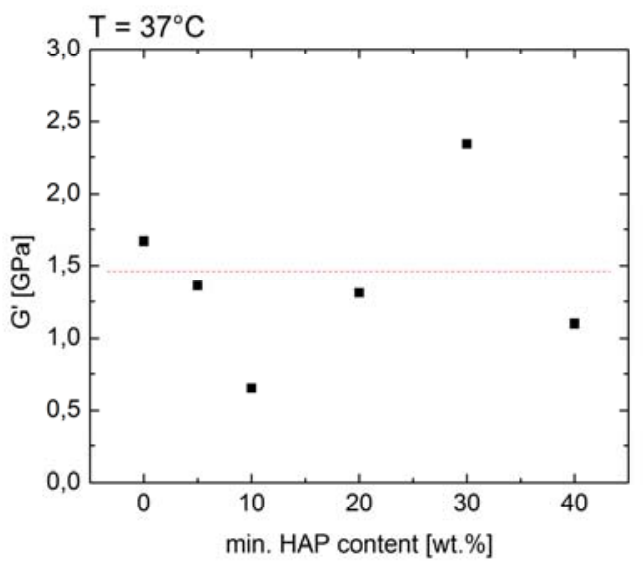

(b)

Fig. 10 Modulus for PLA 4042D containing (a) different filler types and (b) different filler amounts.

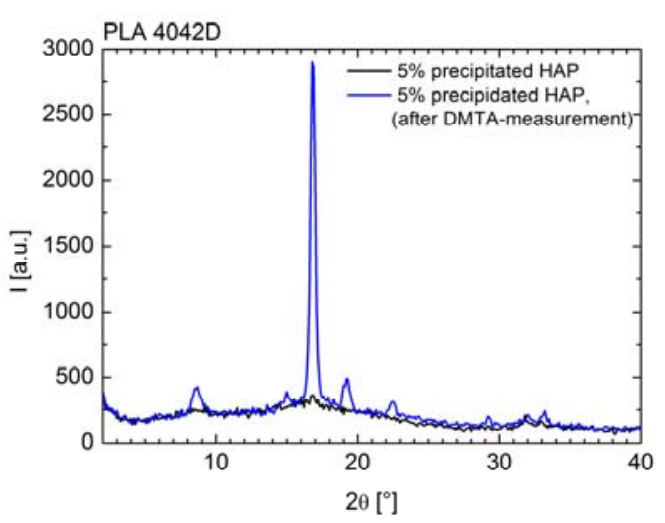

Fig. 11 Wide-angle $X$-ray scattering measurements on injection-molded sample of the same material, after different thermo-mechanical histories.

same sample shows an increased crystallinity of about $10 \%$. The most intense peaks appear at $2 \Theta=17$ and $19^{\circ}$, which suggests the $\alpha$-form of PLLA crystallized in a pseudo-orthorhombic unit cell [20]. Further experiments suggest, that after periods of storage the samples largely maintain their amorphous nature. As a result, implants being applied to a patient can be expected to exhibit the same properties they had after their manufacture, provided the storing temperature is lower than the cold-crystallization temperature.

In summary, all measurements corroborate that the injection-molded samples are mostly amorphous or exhibit only a very low crystallinity after the manufacturing process and, within measurement error limits, stay that way, if kept at room temperature. According to current literature most existing polymeric implants are amorphous. These amorphous implants then initially slowly crystallize in-vitro and in-vivo to a certain percentage $[5,6,22]$, before mass loss and 
crystallinity decrease sets in. It has been discussed that the initial crystallization during degradation is due to rearrangement of the shortening chains (resulting from the hydrolytical chain scission) and the formation of new crystals, while another view is that the crystalline percentage increase simply results from the degradation of the amorphous phase of the polymer $[5,12]$.

The modulus of the injection-molded PLA/filler composites is adequate for non-load-bearing applications. Since the filler type has been shown to have little effect on mechanical properties, its influences on degradation rate and biochemical characteristics are the determining factors in choosing the filler type best suited to the medical application in question.

\subsection{Biochemical Properties}

The biochemical properties were investigated using Phosphate Buffered Saline (PBS) to simulate physiological conditions. For polyester-based materials the results from in-vitro experiments have been found to be a good approximation of an implant's in-vivo behavior, as the biodegradation is the result of an auto-accelerated process of random hydrolytic chain scission without any enzymatic contribution $[6,8,11$, $12,19]$. The complexity of the degradation process leads to many different and often seemingly contradictory phenomena, which have been presented and summarized elsewhere $[6,8,12]$. An implant's biodegradability is especially important since it's one of the critical factors in successful bone repair without stress-shielding [8]. In this study, degradation was evaluated by GPC and the biocompatibility and biotoxicity determined by measuring the $\mathrm{pH}$-value during degradation and by different cell colonization experiments, that show the material's capacity for supporting cell growthand cell proliferation.

Biodegradation experiments were performed in-vitro, with the samples immersed in phosphate buffered saline (PBS) and their molar mass measured at regular intervals over the space of 168 days. Again, samples containing different filler types and different filler amounts were examined (Fig. 12). The degradation rate was found to be higher for samples containing $\mathrm{CaCO}_{3}, \mathrm{Ca}_{3}\left(\mathrm{PO}_{4}\right)_{2}$ or pure precipitated HAP than for those containing all other modifications of HAP, all of which still retained $50 \%-60 \%$ of their molar mass after 168 days in PBS.

For $\mathrm{CaCO}_{3}$ only $23 \%$ relative molar mass were measured, for $\mathrm{Ca}_{3}\left(\mathrm{PO}_{4}\right)_{2} 43 \%$. This shows that HAP-filled samples retain mechanical stability longer under conditions resembling the physiological conditions in the human body. No specific dependence of molar mass reduction due to biodegradation on either screw speed or filler amount was found over the space of 112 days. In other experiments it could be shown that a sample's water intake significantly depends on the filler type used, and that $\mathrm{CaCO}_{3}$ and $\mathrm{Ca}_{3}\left(\mathrm{PO}_{4}\right)_{2}$ facilitate it considerably more than HAP. The increased water intake facilitates a faster hydrolytical degradation. The degradation rate can

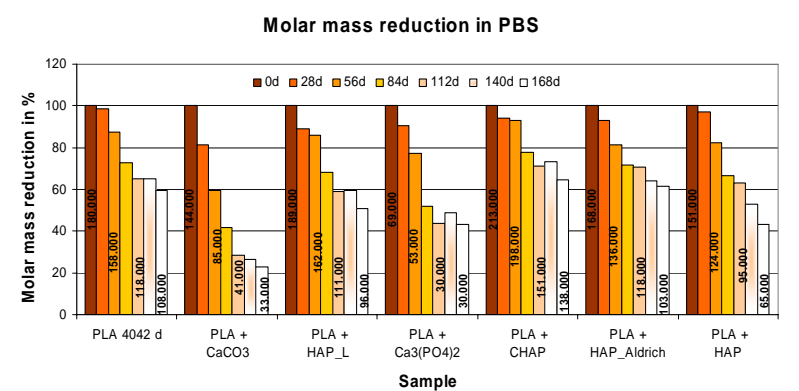

(a)

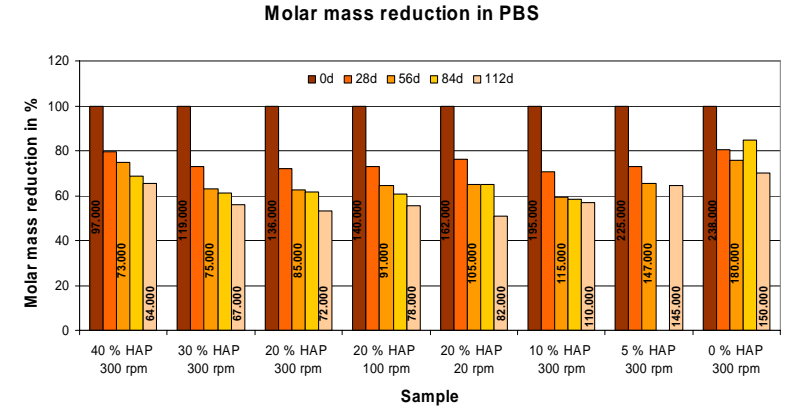

(b)

Fig. 12 Degradation of injection-molded samples containing (a) different filler types and (b) varying HAP amounts after immersion in Phosphate Buffered Saline (PBS) for 168 and 112 days, respectively. 
therefore be influenced by choosing the adequate filler type for different application requirements.

Another possiblefunction of fillers is to act as a buffer. The implant's degradation products usually lead to an acidic environment during the degradation process [19], while the $\mathrm{pH}$-value of human blood is 7.4. Therefore, the degradation products often lead to inflammatory responses of the surrounding tissue. Filler materials with buffering capacity in the physiologically relevant range can be used to avoid these problems [3]. In this study, the measurements show $\mathrm{pH}$-values in the range of 6.6-6.8 for samples containing $\mathrm{CaCO}_{3}$ or $\mathrm{Ca}_{3}\left(\mathrm{PO}_{4}\right)_{2}$ and 7.3 for HAP-containing samples, after 210 days (Fig. 13a).

As it was shown before that the HAP samples degrade much slower than the ones containing $\mathrm{CaCO}_{3}$ or $\mathrm{Ca}_{3}\left(\mathrm{PO}_{4}\right)_{2}$ this does not necessarily mean that HAP is better suited as filler material in biological applications, as not the same amount of HAP has been dissolved out of the sample over the same amount of time. For reliable findings this experiment needs to be continued until the HAP samples have degraded to the same degree.

Fig. 13b shows the dependence of the $\mathrm{pH}$-value on filler amount. Higher amounts of filler lead to a decrease in $\mathrm{pH}$-value; e.g., for $40 \mathrm{wt} \%$ HAP the $\mathrm{pH}$-value is only 6.7 after 168 days. This suggests, that while HAP results in longer mechanical stability it also leads to an acidic environment. Due to the $\mathrm{pH}$-values measured over a maximum of 210 days, it can be said that the samples containing high filler amounts of HAP or either $\mathrm{CaCO}_{3}$ or $\mathrm{Ca}_{3}\left(\mathrm{PO}_{4}\right)_{2}$ are more likely to cause inflammatory responses of the surrounding tissue during that time of degradation.

To determine wether a material is suitable for orthopedic applications, its capability to support and proliferate cell-growth have to be investigated [8]. Bone is a dynamic tissue, which is reshaped by two different cell types that control the amount of tissue formed and resorbed: osteoblasts and osteoclasts. Implant material must therefore support colonization and proliferation of these cells to help the healing process. Osteoblasts are mononucleate cells responsible for bone formation through production of the collagen matrix and its ensuing mineralization. Bone resorption is realized by osteoclasts, which are larger cells containing 15 - 20 nuclei. By acidifying the bone surface where they are attached, osteoclasts dissolve the mineralized bone and break up the organic bone. For cell colonization two types of cells are used: MC3T3-E1-cells, which resemble the human body's osteoblasts and RAW 264.7-cells, which are osteoclast-like cells.

First cell colonization experiments on PLA showed that all samples, for all filler types used, were cytocompatible. The MC3T3-E1-cell colonization tests show good cell proliferation and only a few dead cell

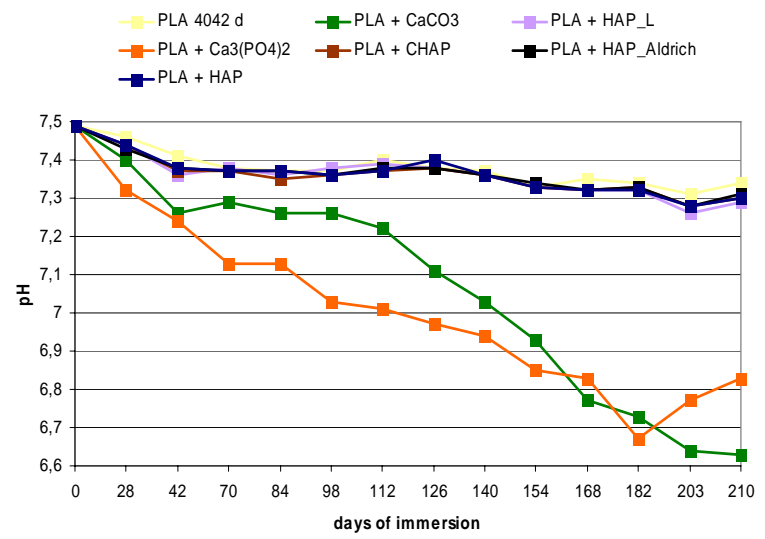

(a)

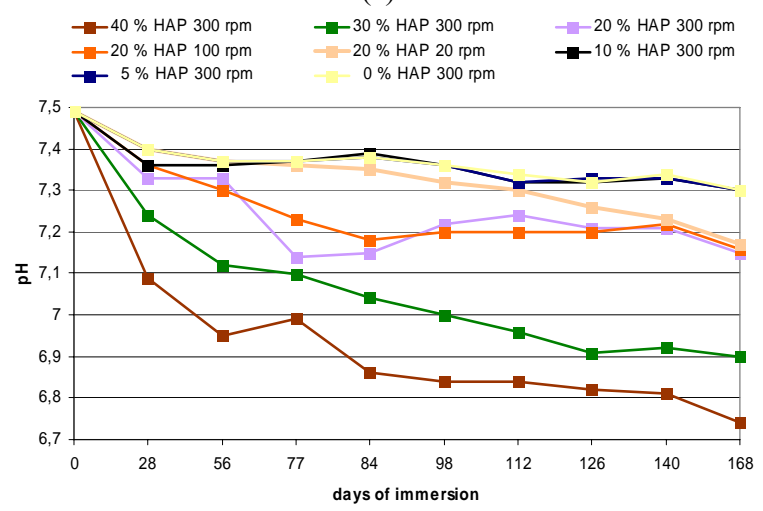

(b)

Fig. 13 The pH-value measured during biodegradation experiments in PBS (Phosphate Buffered Saline) for samples containing (a) $5 \mathrm{wt}$ \% filler material and (b) melt mixed at different screw speeds, containing different amounts of HAP. 
nuclei after 4 days (Fig. 14). Differentiation is achieved by staining. Fluorescein diacetate enters living cells through the cell membrane where it is cloven, releasing fluorescein (green fluorescence). The GelRed ${ }^{\circledR}$ dye on the other hand can only enter through the defective (dead) cell membrane, so that red fluorescence indicates dead cell nuclei.

The WST-1 assayprimarily detects total enzymatic activities that are able to reduce the WST-1 substrate.

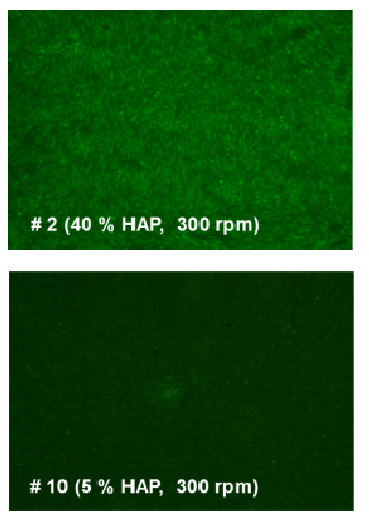

(a)
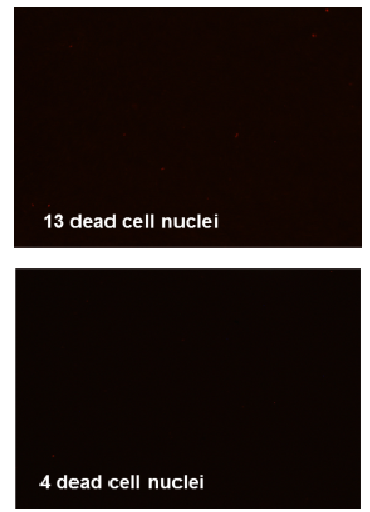

(b)

Fig. 14 MC3T3-E1-cell colonization experiment with (a) live and (b) dead staining.

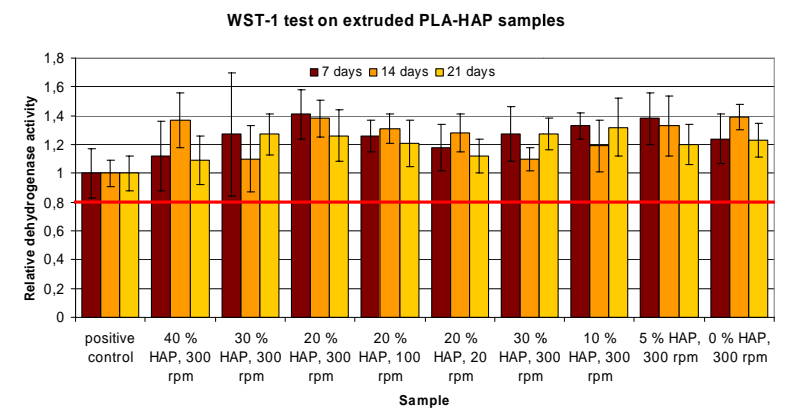

Fig. 15 WST-1 test on PLA 4042D samples containing varying amounts of HAP.

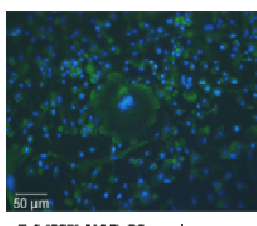

* 4 (20\% HAP, 20 rpm)

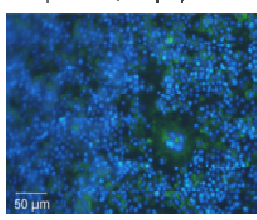

II 15 (10\% HAP, 300 rpm)

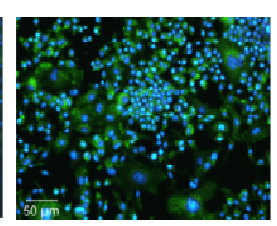

Control sample on glas substrat

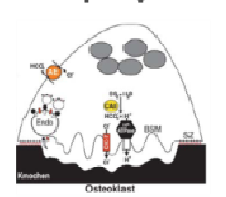

Fig. 16

RAW 264.7-cell colonization on PLA 4042D-substrates containing different amounts of HAP.
Therefore, the rate of WST-1 cleavage by mitochondrial dehydrogenases correlates with the number of viable cells in the culture. The assay found no cytotoxical degradation products for any of the samples, irrespective of filler type, filler amount and processing parameters, over a 21 day period (Fig. 15).

Also, the colonization with RAW 264.7-cells and stimulation of the RAW cells with RANKL led to the formation of multi-nuclear cells on all tested samples as can be seen in Fig. 16. Therefore, all samples wereadequate to support and proliferate cell growth of those cells cultures that are necessary for the remodeling and build-up of new bone material, i.e. all samples were suitable as bone substitution material to be used in medical applications.

\section{Conclusions}

To obtain a composite material that posesses the properties required of an orthopedic implant, the complex system of influencing factors contributing to the material's final characteristics have to be considered. By choosing the right processing conditions the mechanical and biochemical characteristics can be adapted to suit the medical application. Therefore, the influence of the different processing conditions, as well as the material's complete life cycle along the process chain, have been investigated in this study.

Our study shows that melt processing (compounding and injection molding) of biodegradable PLA and bioresorbable inorganic fillers yields largely amorphous composite materials suited to the requirements for medical implants used in bone repair. In our experiments the injection-molded samples exhibited mechanical strengths sufficient for non-load-bearing implant applications, e.g., in fixating comminuted fractures. The process-induced degradation and biodegradation are dependent on the filler material used: HAP-filled samples degrade more slowly than those containing calcium carbonate or calcium phosphate. 
Cell colonization experiments show that all PLA-filler composites produced were cytocompatible, supporting cell adhesion and proliferation of cells resembling osteoblasts and osteoclasts. Nevertheless, not all composites exhibit physiologically acceptable $\mathrm{pH}$-values during biodegradation. Only composites containing less then $30 \%$ HAP had an acceptable $\mathrm{pH}$-value over the duration of the measurements and are therefore less likely to cause inflammatory responses during that time. They are therefore more suitable for orthopedic uses than those containing higher amounts of HAP, or either $\mathrm{CaCO}_{3}$ or $\mathrm{Ca}_{3}\left(\mathrm{PO}_{4}\right)_{2}$, which degrade fast and result in a low $\mathrm{pH}$-value very early on. Nevertheless, further experiments over longer periods of immersion in PBS will have to be carried out to investigate the long-term development of $\mathrm{pH}$-value and degradation.

\section{Acknowledgments}

The work presented was funded by the Bundesministerium für Wirtschaft und Arbeit via the Arbeitsgemeinschaft industrieller Forschungsgesellschaften AiF (Project IGF367 ZBG).

\section{References}

[1] Y. Ikada, T. Hideto, Biodegradable polyesters for medical and ecological applications, Macromolecular Rapid Communications 21 (2000) 117-132.

[2] N.C. Bleach, K.E. Tanner, M. Kellomäki, P. Törmälä, Effect of filler type on the mechanical properties of self-reinforced polylactide-calcium phosphate composites, Journal of Materials Science: Materials in Medicine 12 (2001) 911-915.

[3] A.C. Albertsson, I.K. Varma, Recent developments in ring opening polymerization of lactones for biomedical applications, Biomacromolecules4 (2003) 1466-1486.

[4] T. Ouchi, Y. Ohya, Design of lactide copolymers as biomaterials, Journal of Polymer Science: Part A: Polymer Chemistry 42 (2004) 453-462.

[5] E.A.R. Duek, C.A.C. Zavaglia, W.D. Belangero, In vitro study of poly(lactic acid) pin degradation, Polymer 40 (1999) 6465-6473.

[6] M. Vert, Lactide polymerization faced with therapeutic application requirements, Macromolecular Symposia 153
(2000) 333-342.

[7] L.S. Nair, C.T. Laurencin, Biodegradable polymers as biomaterials, Progress in Polymer Science 32 (2007) 762-798.

[8] A.G.A. Coombes, M.C. Meikle, Resorbable synthetic polymers as replacements for bone graft, Clinical Materials 17 (1994) 35-67.

[9] P.S. Uskokovic, C.Y. Tang, C.P. Tsui, N. Ignjatovic, D.P. Uskokovic, Micromechanical properties of a hydroxyapatite/poly-l-lactide biocomposite using nanoindentation and modulus mapping, Journal of the European Ceramic Society 27 (2007) 1559-1564.

[10] C. Schiller, E. Epple, Carbonated calcium phosphates are suitable $\mathrm{pH}$-stabilising fillers for biodegradable polyesters, Biomaterials 24 (2003) 2037-2043.

[11] Y. Cha, C.G. Pitt, The biodegradability of polyester blends, Biomaterials 11 (1990) 108-112.

[12] M. Hiljanen-Vainio, P. Varpomaa, J. Seppälä, P. Törmälä, Modification of poly(L-lactides) by blending: Mechanical and hydolytic behavior, Macromolecular Chemistry and Physics 197 (1996) 1503-1523.

[13] C. Wang, Y. Sheng, Haribala, X. Zhao, J. Zhao, X. Ma, Z. Wang, A novel aqueous-phase route to synthesize hydrophobic $\mathrm{CaCO}_{3}$ particles in situ, Materials Science and Engineering: C 27 (2007) 42-45.

[14] S. Berger, E. Müller, M. Schnabelrauch, Influence of methacrylate-containing surface modifiers on the mechanical properties of nano-hydroxyapatite/polylactide network composites, Materials Letters 63 (2009) 2714-2717.

[15] Z. Hong, X. Qiu, J. Sun, M. Deng, X. Chen, X. Jing, Grafting polymerization of -lactide on the surface of hydroxyapatite nano-crystals, Polymer $45 \quad$ (2004) 6699-6706.

[16] J. Hao, T. Keller, K. Cai, E. Klemm, J. Bossert, K.D. Jandt, The effect of d,l-Lactidyl/e-caproyl weight ratio and chemical microstructure on surface properties of biodegradable poly (d,l-Lactide)-co-poly ( $\epsilon$-Caprolactone) random copolymers, Advanced Engineering Materials 10 (2008) B23-B32.

[17] L. Zhang, C. Xiong, X. Deng, Biodegradable polyester blends for biomedical application, Journal of Applied Polymer Science 56 (1995) 103-112.

[18] H. Tsuji, K. Ikarashi, In vitro hydrolysis of poly(L-lactide) crystalline residues as extended-chain crystallites: Part 1. Long-term hydrolysis in phosphate-buffered solution at 37 degrees C, Biomaterials 25 (2004) 5449-5455.

[19] P. Mainil-Varlet, R. Curtis, S. Gogolewski, Effect of in 
632 PLA-Based Biodegradable and Cytocompatible Implant Materials: Material Development, Processing and Properties

vivo and in vitro degradation on molecular and mechanical properties of various low-molecular-weight polylactides, Journal of Biomedical Materials Research 36 (1997) 360-380.

[20] N. Ignjatovic, E. Suljovrujic, J. Budinski-Simendic, I. Krakovsky, D. Uskokovic, Evaluation of hot-pressed hydroxyapatite/poly-L-lactide composite biomaterial characteristics, J. Biomed Mater Res. B: Appl Biomater 71
(2004) 284-294.

[21] P.C. Dechow, G.A. Nail, C.L. Schwartz-Dabney, R.B. Ashman, Elastic properties of human and mandibular bone, American Journal of Physical Anthropology 90 (1993) 291-306.

[22] C.A. Landes, A. Ballon, C. Roth, In-patient versus in vitro degradation of P(L/DL)LA and PLGA, J. Biomed. Mater. Res. B: Appl Biomater 76 (2006) 403-411. 